Current Issues of Education and Science, 2021

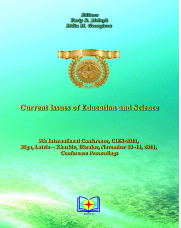

DOI: $\underline{\text { https://doi.org/10.26697/9786177089147.2021.13 }}$

\title{
Medical Gloves and Their Importance for the Safety of Patients and Medical Personnel
}

\author{
Tatiana V. IARMAK ${ }^{1}$ \\ ${ }^{1}$ Municipal Health Care Institution \\ "Kharkiv Regional Medical College”, Ukraine \\ Corresponding Author Details \\ Tatiana V. IARMAK, pi23rola@gmail.com
}

Received: 25.08.2021; Accepted: 30.09.2021; Published: 17.12.2021

\section{Brief Summary}

Background: As medical staff is in a constant contact with various negative factors such as biological, chemical, drugs, and disinfectants, the hands of medical staff require an additional protection barrier, which is the use of medical gloves. Hand hygiene of the medical staff in the modern prevention of nosocomial infections is one of the most important practices, but it is neglected oftentimes. In addition to hand washing and hand disinfection, medical gloves effectively protect patients and medical staff from potentially dangerous infectious agents.

The aim of the study: To show and emphasize the importance of medical gloves for the safety of patients and medical personnel in prevention of the healthcare-associated infections.

Methods: Due to the mounting rates of infectious diseases among the population during the execution of surgeries and invasive procedures (intravenous and intramuscular manipulations, endoscopic examinations, hemodialysis, plasmapheresis, etc.), the risk of contracting occupational diseases, as well as the cases of patients getting infected as the result of the medical care provision have significantly increased over the past decades.

Results: It was examined the importance of medical gloves in the prevention of infections related to the provision of medical care, in particular nosocomial infections; described types, kinds and characteristics 
of medical gloves, their barrier properties, studied the selection criteria, the necessity of use. The material presented is essential for the work of medical staff in the healthcare facilities, laboratories etc.

Conclusions: Considering the fact that the selection of medical gloves is based on the risk assessment, the correct use of medical gloves is a bottom line for the safety and protection of patients and medical personnel from the health-associated infections.

\section{Keywords:}

medical gloves, hand hygiene, hands, prevention, healthcare-associated infections, medical personnel, patient.

\section{Background:}

One of the most pressing and vital problems in modern medicine for all the countries in the world is the problem of the healthcare associated infections (HAIs), in particular, nosocomial infections. A high mortality rate, socio-economic, moral damage are the reasons why HAIs pose one of the most serious threats to the health of the patient and the staff. To minimize the risks of nosocomial infections, it is necessary to use preventive measures. The use of medical gloves is an important preventive measure to combat the HAIs. Medical gloves create additional barrier and protect patients and the staff from contracting various infectious agents. Damaged and contaminated gloves create a higher risk of infection for both parties.

There are no standards of the glove selection in any country in the world (Kampf, 2005). Medical gloves are classified according to the type of material, shape, texture, purpose and scope.

Gloves are divided into diagnostic (examination); surgical - with an extended cuff; special purpose surgical gloves such as gynecological, orthopedic - extremely durable, ophthalmic - hypersensitive and other); protective, sterile, non-sterile.

Each type of glove, in addition to its intended use, provides different levels of protection. Gloves are not only intended for medical purpose, but are also means of individual protection, depending on the purpose. Medical gloves should be of the correct size, fit snugly around the hand, maintain a high tactile sensitivity, but at the same time be durable and resistant to the risk of damage during surgical operations, manipulations and other medical procedures, which depends on the density (the frequency of the gloves puncture is from 4.6 to $82.5 \%$ ) (Zueva, 2000); protect from biological agents, the influence of aggressive chemicals; be hypoallergenic; be airtight 
(according to the European standard EN 455-1, AQL - "acceptable level of quality", the hermeticity index should not exceed 1.5).

The staff, whose work involves blood and other human biological liquids, falls into a category of higher risk and requires gloves as an essential part of the healthcare worker's clothing. Disposable medical gloves are used to protect the hands of medical personnel and create a protective barrier between the patient and medical personnel in performance of their professional duties.

The aim of the study. To show and emphasize the importance of medical gloves for the safety of patients and medical personnel in prevention of the healthcare-associated infections.

\section{Methods:}

The Order of the Ministry of Health of Ukraine of 21.09.2010 No. 798 approved methodological recommendations "On surgical and hygienic hand-washing of medical personnel", where clause 5 regulates the use of medical gloves. The Order of the Ministry of Social Policy of Ukraine of 29.11.2018 No. 1804 approved methodological recommendations 'On minimum safety and health requirements for the use of personal protective equipment by the workers in their workplace'. In May 2019, at the 72nd session of the World Health Assembly in Geneva, Ukrainian delegation took part in the discussion of patient safety in the provision of healthcare medical care. On September 4th, 2019, the Patient Safety Day was established in Ukraine by the decree of the President.

\section{Results:}

Nowadays there is a wide range of gloves. They are made of different materials (latex, nitrile, neoprene etc.), produced in different sizes (surgical: from 5-5.5 to 9-9.5; diagnostic - XS, S, M, L, XL), colors (colorless, light blue, blue, black, purple, pink and other- the color marks the material the glove is made of), shapes (universal-no difference for the right and left hand, anatomical - with differences for the right and left hand), packaging type (sterile gloves are individually packed one pair per package, and for double gloves - two in a package; non-sterile gloves are packed in a cardboard box from 50 to 100 pairs in one package or can be packed in a glove dispenser). They have specific characteristics for each type, etc.

The technical characteristics of gloves are determined by the European standards: EN 455 - disposable medical gloves, EN 420 - defines the general requirements for the protective gloves - ergonomics, quality of the material, harmlessness, size, practicality, level of protection and other 
characteristics. EN 374 - defines the level of protection against chemicals and microorganisms; EN 388 - defines the level of protection against mechanical damage. Each packaging has a pictogram that has numbers to indicate the level of protection. In recent years, the AVPP test - a dynamic test for resistance to blood-borne infections, has been carried out during a regular work shift. It is used to assess the barrier protection against viruses during flexion - extension, pressure, friction.

Specific knowledge is required to make the right choice of a medical gloves (Bearman et al., 2014). Medical staff must understand and know about the importance and utter necessity of the safe working conditions: be familiar with the characteristics of various types and kinds of gloves, analyze the possible risks of infection in order to understand when and for what purpose (surgery, manipulation, procedure) they need to and can be used.

The use of gloves is neither a substitute for a hand washing with soap and water, nor for a hygienic or surgical hand disinfection, but is an additional protective clothing accessory of the medical personnel outfit in prevention of HAIs.

The use of medical gloves is obligatory in all the cases where there is a potential contact with blood, other biological liquids, mucous membranes or non-intact skin. Medical gloves should only be put on clean and completely dry hands. No glove material can guarantee $100 \%$ protection against all infectious agents or chemicals, so hands should be disinfected after removing gloves.

The correct donning and doffing as well as the correct use (indications, suitability in size, integrity, wearing duration, etc.) prevents the contamination of the gloves and the hands of medical personnel. Gloves that were used must be disinfected. For this they are soaked in special containers (container for disinfection and pre-sterilization) with a disinfectant solution of a certain concentration and for a certain amount of time (according to the methodological recommendations of disinfectant). Afterwards, they are being rinsed, dried, and disposed of.

The material (latex, nitrile, vinyl and others), which is used to make gloves and the conditions of their use (the procedure types, manipulations, duration, work with biological body fluids, various medicinal, chemical substances etc.) affect their barrier function.

The glove characteristics, such as elasticity, degree of permeability, ease of donning, electrical conductivity, must be adapted for the peculiarities and specifics of the job of the healthcare workers. Latex is rightfully the number one material. Latex gloves are affordable, fit the hand properly, have high tactile sensitivity, tear strength, high resistance to 
chemicals, but proteins and the powder contained in latex can cause various allergic reactions such as contact dermatitis, urticaria, Quincke's edema, even up to anaphylactic shock. The replacement (since 1997) of the powdered latex gloves by the powdered-free ones resulted in a reduction of latex allergy.

Nitrile gloves have become an alternative to the latex gloves. They are hypoallergenic, reliable, comfortable, highly resistant to tear, puncture, and cut, snugly fit the hand. These gloves are widely used in all medical fields.

The tactile gloves, made of mixture of styrene, ethylene and butadiene as well as the vinyl or PVC gloves are hypoallergenic, lowelastic, anatomical in shape, resistant to chemicals and are frequently used for the examination of the patient.

The materials used to manufacture modern medical gloves and the manufacturing technologies are constantly being improved. Lately, the synthetic gloves made of neoprene (chloroprene rubber) have become widely used. Due to their similarity of chemical structure with latex in elasticity and a high tactile sensitivity, they fit the hand snuggly, what allows to reduce the fatigue of the hands of medical personnel during surgical interventions, various manipulations.

Neoprene gloves are extremely resistant to cytostatic, which makes them widely used in oncology. Suitable for a long-term use; resistant to potentially infected biological fluids (blood, semen, saliva, etc.), with aggressive chemicals, hypoallergenic.

The invention of chainmail gloves, invented for the safety of surgery and manipulations with a high risk of infection, fostered the worldwide decline in mortality rates among doctors from such dangerous infections as HIV/AIDS, hepatitis B, C. The chainmail gloves are made of a material that is resistant to cuts and punctures due to a special barrier layer. The creation of the double medical gloves (the lower glove differs from the upper in color) with a puncture indication reduces the risk of blood-borne infections by surgeons of different profile (gynecologists, ophthalmologists, otolaryngologists, etc.), doubled the protection and allowed to detect damage - a contrasting spot formed in the puncture area signals that there is a perforation, making it possible to replace the glove in time (Tietjen, 2003; Zueva, 2000).

Three-layer surgical gloves with an increased degree of protection have become an innovative breakthrough in medicine. Due to a microdroplet disinfectant (a mixture of quaternary ammonium and biguanidechlorhexidine digluconate) between the layers of the gloves, the risk of infection for medical personnel and patients has been reduced. 
In the event of an accidental puncture or cut, the release of the disinfectant liquid at the injury site immediately provides protection. They are used in all types of surgical operations, but are especially appreciated in orthopedics and obstetrics.

\section{Conclusions:}

Medical gloves are a mandatory attribute of medical clothing. The use of medical gloves is a versatile preventive measure that considerably reduces the risk of healthcare-associated infections. Improvement of materials and manufacturing technologies can significantly improve the quality of medical gloves, expand the scope of their application and seriously raise the level of barrier protection against all kinds of infectious agents and chemicals.

\section{Conflicts of interests:}

The author declares that there is no conflict of interests.

\section{Source of support:}

This research did not receive any outside funding or support.

\section{References}

Bearman, G. M. L., Stevens, M., Edmond, M. B., \& Wenzel, R. P. (2014). A Guide to infection control in the hospital (5th ed.). ISID. https://www.dspsv.ro/uploads/epidemiologie/5thEd_GuideInfectio nControl_forWEB.pdf

Kampf, H. (Ed.). (2005). Hyhyena ruk $v$ zdravookhranenyy [Hand hygiene in healthcare]. Zdorovia. https://www.twirpx.com/file/1293542/ [in Russian]

Laine, T., \& Aarnio, P. (2004). Glove perforation in orthopaedic and trauma surgery. A comparison between single, double indicator gloving and double gloving with two regular gloves. The Journal of Bone and Joint Surgery, 86(6), 896-900. https://doi.org/10.1302/0301620x.86b6.14821

Mischke, C., Verbeek, J. H., Saarto, A., Lavoie, M. C., Pahwa, M., \& Ijaz, S. (2014). Gloves, extra gloves or special types of gloves for preventing percutaneous exposure injuries in healthcare personnel. The Cochrane database of systematic reviews, 3, CD009573. https://doi.org/10.1002/14651858.CD009573.pub2

Shalimov, A. A., Grubnik, V. V., Tkachenko, A. I., Osipenko, O. V., \& Chetverikov, S. G. (2001). Infekcionnyj kontrol $v$ hirurgii [Infection control in surgery]. https://www.twirpx.com/file/530232/ [in Russian] 
Tanner, J., \& Parkinson, H. (2002). Double gloving to reduce surgical cross-infection. The Cochrane database of systematic reviews, 3 , CD003087. https://doi.org/10.1002/14651858.CD003087

Tietjen, L., Bossemeyer, D., \& McIntosh, N. (2003). Infection prevention guidelines for healthcare facilities with limited resources. JHPIEGO Corporation. https://pdf.usaid.gov/pdf_docs/Pnact433.pdf

Zueva, L. P. (Ed.). (2000). Rekomendacii po mytju $i$ antiseptike ruk. Perchatki $v$ sisteme infekcionnogo kontrolja [Recommendations for hand washing and antisepsis. Gloves in the infection control system]. Center for Infection Control. https://window.edu.ru/catalog/pdf2txt/310/58310/28231 [in Russian]

\section{Information about the author:}

Iarmak Tatiana Viktorivna - https://orcid.org/0000-0001-5371-2958; Lecturer of the Department of Advanced Training of Junior Medical Specialists, Municipal Health Care Institution "Kharkiv Regional Medical College", Kharkiv, Ukraine.

Research interests: medicine, education, psychology, new technologies.

\section{Cite this article as:}

Iarmak, T. V. (2021). Medical gloves and their importance for the safety of patients and medical personnel. In Yu. B. Melnyk, \& L. M. Georgieva (Eds.), Current Issues of Education and Science. 9th International Conference, CIES-2021, Riga, Latvia - Kharkiv, Ukraine, November 10-13, 2021, Conference proceedings (pp. 104-110). KRPOCH. https://doi.org/10.26697/9786177089147.2021.13

\section{Copyright information:}
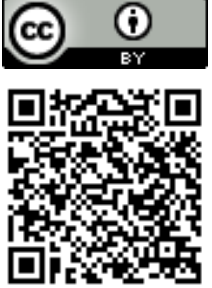

The published paper are licensed under a Creative Commons "Attribution" 4.0 Worldwide

The electronic version of this article is complete. Full or partial reproduction of article is allowed, citing to the source, author(s) and DOI. An electronic copy of the Conference proceedings in open access is available via the $\mathrm{KRPOCH}$ Publishing website https://publisher.culturehealth.org 